\title{
Osteonecrosis of Femoral Head: Efficacy of Core Decompression and Non Vascularised Fibular Graft
}

\author{
Dr.Riyaz N.N ${ }^{1}$, Dr.Sunil.V ${ }^{2}$, Dr.Nikhil Narayanan ${ }^{3}$, \\ ${ }^{1}$ associate Professor Of Orthopaedics \\ ${ }^{2}$ professor Of Orthopaedics \\ ${ }^{3}$ department Of Orthopaedics Pariyaram Medical College,Kannur
}

\begin{abstract}
:
Background: We present the results of osteonecrosis of femoral head treated by core decompression with non vascularized fibular graft.

Patient and Methods: 20 patients with osteonecrosis femoral head treated between 2012 and 2015 were included in the study. We performed core decompression and non vascular fibular grafting. All patients were evaluated clinically and radiologically and were belonging to pre collapsing stage (I and II) according to Ficat and Arlet classification. Outcome was assessed with Harris hip score.

Results: We achieved good subjective and functional outcome in patients.

The results were considered as a success if there was no progression of disease, confirmed radiologically,or no subsequent surgeries were required. In our series, 14 patients had excellent outcome and all of them returned to their previous activity. Progressive pain and progression of collapse was seen in 5 patients and they eventually ended up in total hip replacement. 1 patient expired during the study period due to medical co morbidities. The mean Harris hip score was 72.3 at the end of follow up period.

Conclusion: Management of osteonecrosis of femoral head with non vascularized fibular graft proved to be an excellent treatment modality compared to other non operative methods. The procedure provides decompression of the avascular lesion and removal of the necrotic bone in order to interrupt the cycle of ischemia and interosseous hypertension. However long follow-up period is absolutely necessary for accessing the long term outcome.
\end{abstract}

Keywords: Avascular necrosis,coredecompression,fibulargraft,harris hip score

\section{Introduction}

The condition was first described in 1738 by Alexander Munroe. In mid 1800s Cruveilhier attributed the disorder to an aberration of circulation in the femoral head. Simply defined, osteonecrosis means "dead bone." The "avascular" state of the necrotic bone is the result of a loss of circulation from numerous potential causes, which includes alcohol abuse, gout, Caisson disease, Gaucher disease, renal osteodystrophy, hypercoagulable states, sickle cell anemia, systemic steroid use, and trauma. In many cases, a cause cannot be identified, hence designated as idiopathic osteonecrosis.Male to female ratio is about 4:1.

The hypotheses regarding its pathogenesis include direct cellular toxicity, coagulopathic states, hyperlipidemia with fat emboli, vascular interruptions or abnormalities, and elevated bone marrow pressure. None of these theories can fully account for the variety of causes and the process is most likely multifactorial. Ficat and Arlet, based on radiographic changes is the most commonly used classification system for osteonecrosis of the femoral head.

Patients are typically asymptomatic in early stages with plain x-rays showing normal morphology. Eventually, symptoms start as groin pain associated with ambulation and as disease progresses,radiographic changes begin to appear in the form of increased density or lucency in the femoral head. Cresent sign is pathognomonic though it appears only in the late stages. In the end stages of the disease, femoral head collapse occurs, and severe arthritic changes may be seen on both sides of the joint

principle of core decompression is based on the belief that the procedure relieves intraosseous pressure caused by venous congestion, allowing improved vascularity and possibly slowing the progression of the disease. Success rates of core decompression can be further increased by structural bone grafting techniques after core decompression using cortical bone, cancellous bone, vascularized bone graft, and debridement of necrotic bone from the femoral head. We present our results in patients who belonged to pre collapse stage underwent core decompression andnon vascularized fibular graft. 
Osteonecrosis Of Femoral Head: Efficacy Of Core Decompression And Non Vascularised ....

\section{Patients And Methods}

A prospective study was carried out from 2012 to 2015 in our institution,Department of Orthopaedics Academy of Medical Sciences, Pariyaram,Kannurcomprising of 20 patients in which a diagnosis of osteonecrosis of femoral head was made.Clinical examination was conducted in all patients revealed pain with range of motion and ambulation. Limitation of internal rotation in both flexion and extension were found with passive internal rotation and extension being particularly painful. Further evaluation was done with plain $\mathrm{x}$-rays and MRI scan. Study group comprised of 20patients-13 males and 7 females. 6 patients showed bilateral involvement of femoral head osteonecrosis and underwent surgeries in the same sitting.Patients were staged using Ficat and Arlet classification. All the patients belonged to precollapse stage of femoral head osteonecrosis.

The age of patients in study group ranged from 33 to 74 years. The mean age was 54 years. Mean follow up time was two and half years.

\section{Operative Technique}

1.Harvesting of non vascular fibular graft Initial part of surgery include harvesting non vascular fibular graft preferably from contralateral side. The proposed length of fibula was marked over the outer aspect of leg. 2 anterolateral incisions were made $1 \mathrm{~cm}$ each over the proximal and distal end of proposed length of graft. Incision was made along the posterior margin of fibula. Superficial and deep fascia were divided. A plane between Soleus posteriorly and peroneal muscles anteriorly was developed.After elevation periosteum maximally from the anterior, lateral and posterior surfaces, the proximal and distal end of proposed fibula is cut as per roof head cut fashion. The graft was gently rotated inside to ensure that it was free from soft tissues and delivered through the distal incision wound was closed in layers.

2. Core decompression and cortical grafting The surgery was performed through Hungerford's technique under epidural anesthesia with the patient in a supine position on a fracture table. A $2-3 \mathrm{~cm}$ mid lateral longitudinal incision centered over the sub trochanteric region. The fascia lata is split in the direction of its fibres.Under Carm guidance, a $3.2 \mathrm{~mm}$ threaded guide pin is placed between the lateral cortex of the inferior portion of greater trochanter and the distal portion of the lesser trochanter (figure 1). The tip of guide pin was directed into the centre of the diseased portion of the bone.The guide pin was overreamed with an $8 \mathrm{~mm}$ reamer(figure 2).

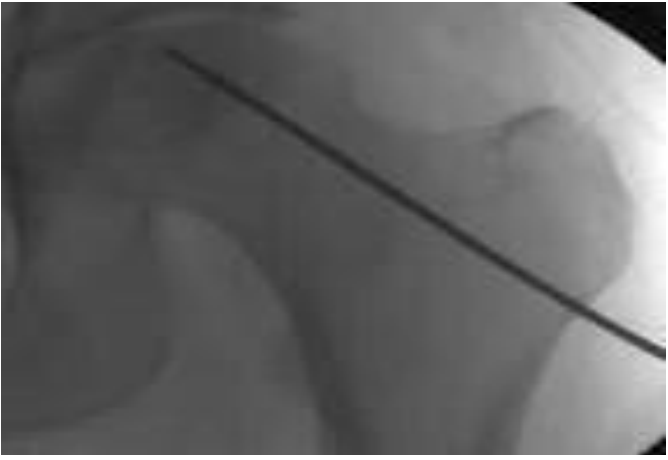

Figure 1

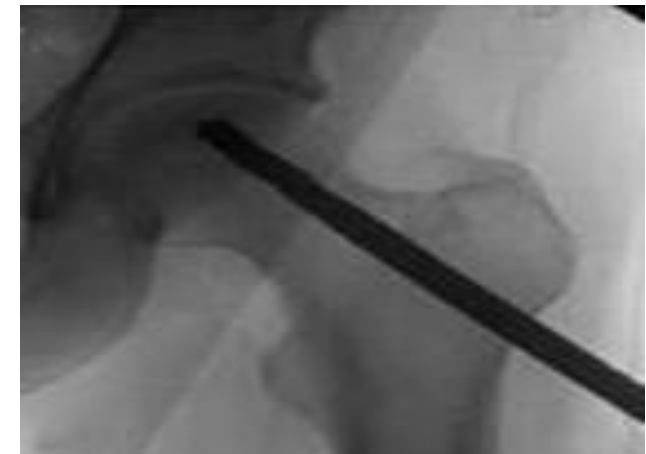

Figure 2

With the aid of an $8 \mathrm{~mm}$ hollow trephine, a core of bone was removed under $\mathrm{C}$ arm guidance.Carewas taken not to damage the subchondral lamina of the femoral head.

\section{Post Operative Care}

For the fibular graft site,compression bandage was applied until removal of sutures. Active range of motion exercise of knee and ankle started during the immediate post operative period. Partial weight bearing was allowed after 4-6 weeks post operatively.Full weight bearing with walker support started after 3 months.

\section{Evaluation}

patients were followed up at 6 weeks, 3 months,6months, one year and one and half years. We evaluated the status of the patient with regards to pain, distance walked with or without support, climbing of stairs, sitting, squatting and clinically examined range of movement of hip using Harris hip score, according to which the score $<70$ was poor, 70-79- fair,80-89-good,90-100-excellent. Follow up check x rays were taken. 


\section{Results}

The patients had good clinical improvement with relief of pain and improved range of movements. 12 were males and rest females. The left hip was involved in 9 cases,right in 5 cases.Bilateralinvolvement was seen in 6 cases.One patient expired during the study period due to multiple medical comorbidities. 12 patients belonged to stage I and 8 hips were classified into stage II.Radiological progression and increased pain was seen in 6 patients which eventually ended up in total hip replacement at the end of follow up period.
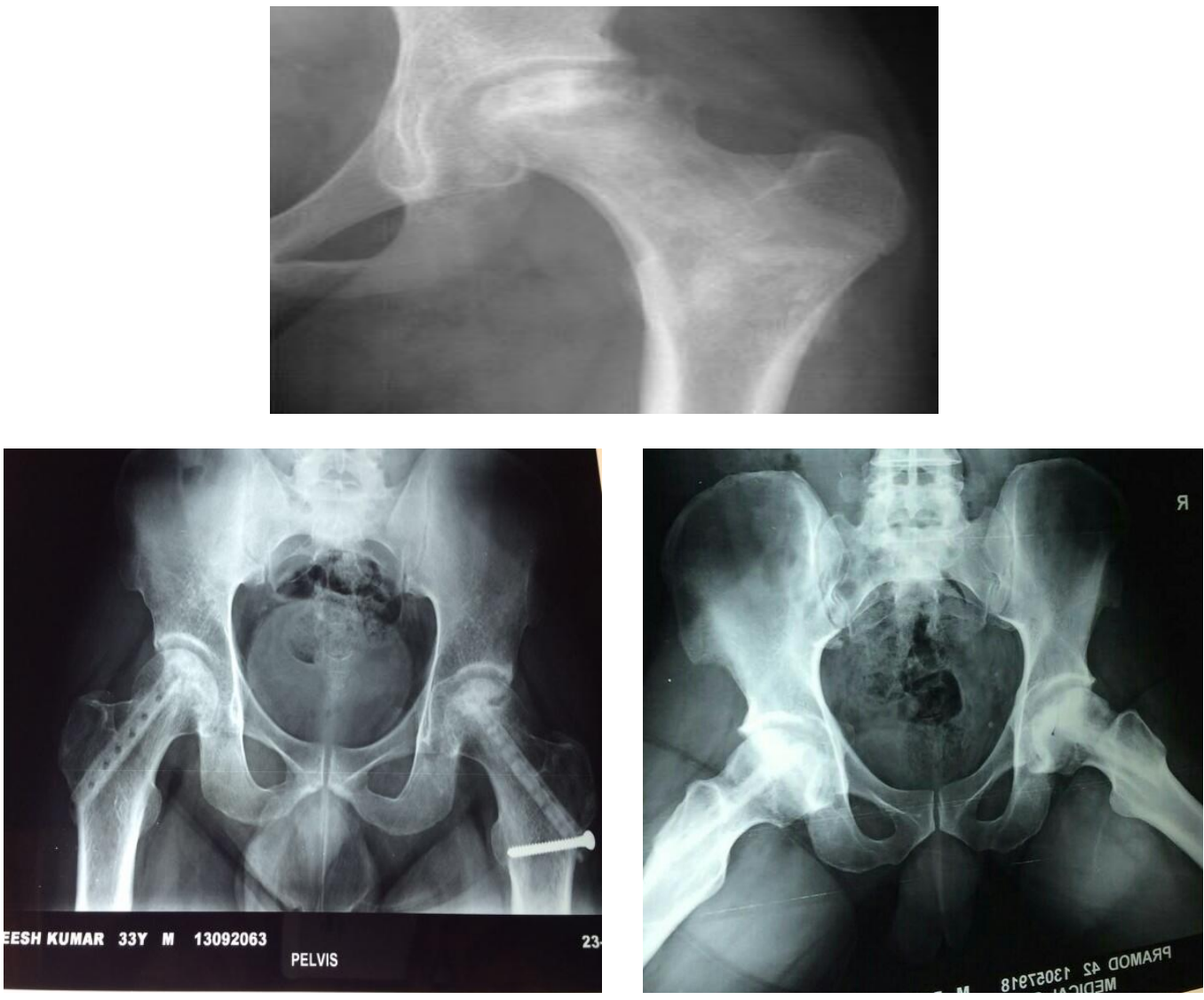

The mean follow up time was two and half years. Out of the 20 patients, at the end of follow up period, 14 patients showed Harris hip score with symptomatic relief of pain, limping. The range of movement of affected hip joint increased which was evident from the range of day to day physical activities they were able to perform post operatively when compare to their pre operative status. They showed a mean increase of in Harris hip score by 14.2 points.

6 patients progressed in the disease stage according to Ficat and Arlet classification and their Harris hip score decreased by a mean value of 10.3 . Of the etiologies, our patients were grouped as per the following chart.

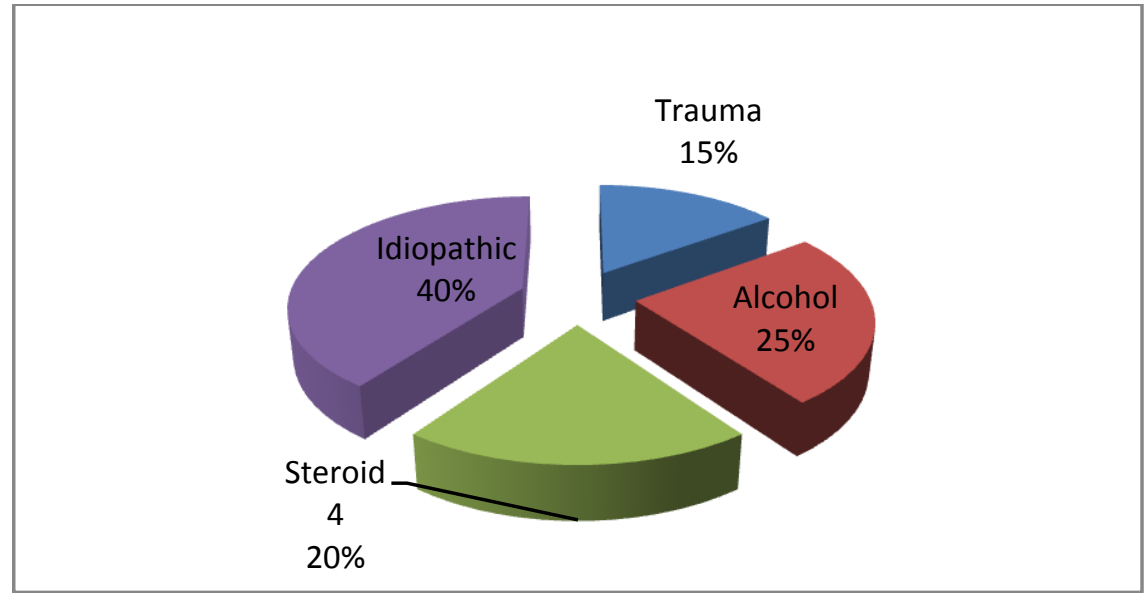




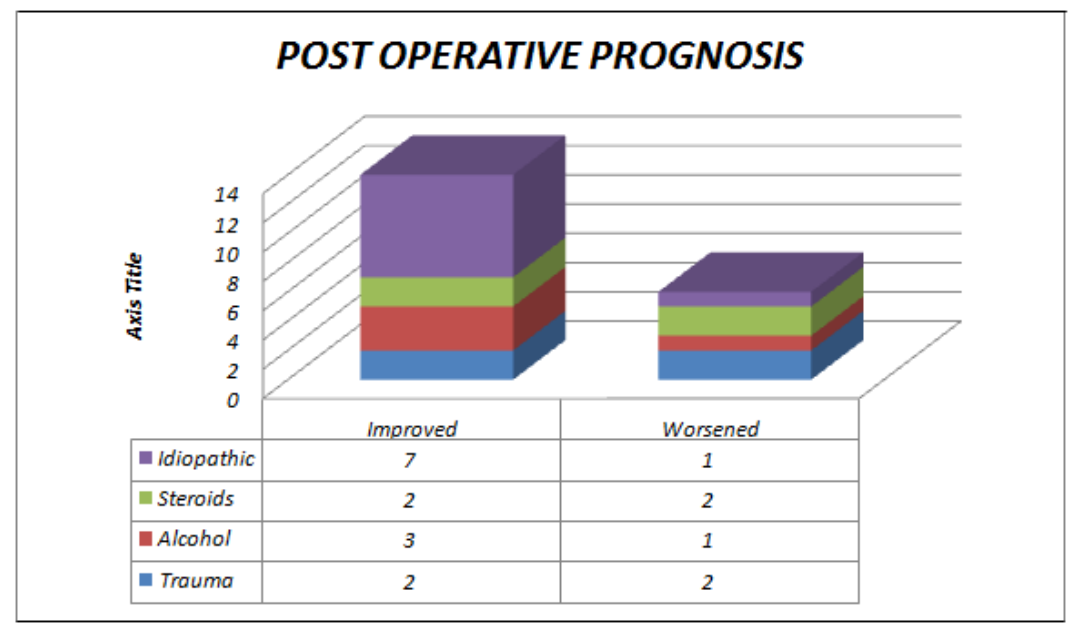

At the end of follow up period,13 patients had excellent subjective and functional outcome. All of them returned to previous activities and had good pain relief.Squatting,exercises, getting up from sitting position which were difficult in the initial stages became easier at the end of follow up period.
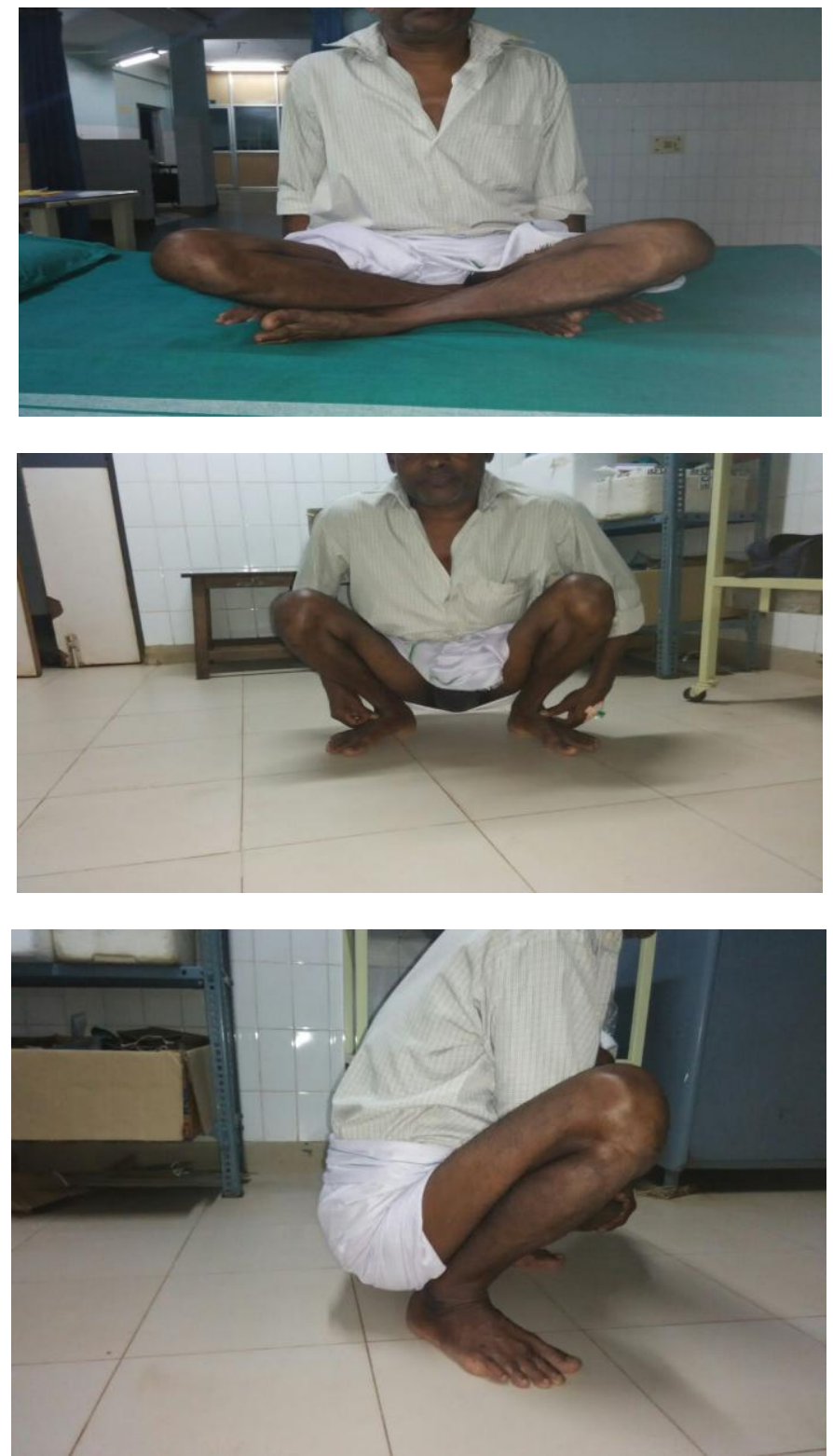


\section{Discussion}

Treating ischemia of femoral head has become more common since many of the cases are detected in early stages.Early diagnosis before the appearance of radiological changes is very important in the treatment of avascular necrosis.Diagnosis is based on clinical examination,bone scan,CT scan and MRI. Xray is of very limited significance in early stage of the disease.MRI has dramatically improved the diagnosis of avascular necrosis,especially in the early stages when there are only bone marrow changes. Signal changes in the anterosuperior part surrounded a rim of low intensity changes in $\mathrm{T} 1$ and $\mathrm{T} 2$ weighted images is pathognomonic of osteonecrosis.

Core decompression reduces the symptoms of pre collapse stage of ischemic necrosis because of reduction of pressure in compartment.There is absolutely no role for conservative management in osteonecrosis of femoral head.Steinberg et al. reported that progression occurred in $92 \%$ of 48 hips that had undergone non operative management ${ }^{23}$. No drugs have been useful and specific in the treatment of avascular necrosis.Rationale for the treatment of osteonecrosis of femoral head requires a lot of consideration. Age of the patient,bilateralinvolvement,associateddiseases,functional demands of patients,stage of the disease.The ideal treatment modality should be simple,reproducible and with low morbidity and mortality.It should not increase the difficulty of a subsequent total hip replacement.The main advantages of non vascularized graft are significant reduction in pain,earlymobilization,easy and technically less demanding procedure,less chances of donor site morbidity,less chances of iatrogenic subtrochanteric fractures and shorter operative time.

In 2000, Castro and Barrack analyzed the results of 22 studies involving application of core decompression, including eight studies involving nonoperative treatment. They concluded that the outcome of core decompression performed in the early stages is significantly better than that of conservative therapy.

The efficacy of core decompression and its limited indications are controversial topics in the literature. ${ }^{7,8}$ The choice of technique depends on the number of tunnels drilled and the diameter of the tunnels. Mont et al reported a patient series followed up for 2 years, and $71 \%$ of 45 stage I hip cases treated with a 3.2 $\mathrm{mm}$ multiple hole procedure had positive results.

In addition to core decompression, electrical stimulation, growth factors, bone morphogenic protein, autologous bone marrow cell concentrate, and tantalum rod implantation have been used to increase efficacy. Vascularized or nonvascularized bone grafts have also been used in combination with core decompression. Electrical stimulation has been reported to have a positive impact in patients who were treated with core decompression. ${ }^{8,9}$ Mont et al reported positive outcomes in $18(86 \%)$ of 21 hips with allografts impregnated with bone morphogenic protein.10 In 2004, Liebermann et al used an autogenous fibular graft with $50 \mathrm{mg}$ of bone morphogenic protein in his surgical series of 17 hip cases (15 stage IIA, 1 stage IIB, 1 stage III). They reported that $93 \%$ of hips with stage IIA disease had positive results, and that three with stage IIA, IIB, or III disease required total hip replacement.11 In another study, the tunnel was filled with either an autogenous iliac bone graft, an autogenous iliac bone graft \pm demineralized bone matrix, or an allogenic bone graft after core decompression. Overall, positive results were reported for $65 \%$ of cases. ${ }^{12,13}$

Autologous concentrated bone marrow-derived mononuclear cell concentrate was first used in the treatment of osteonecrosis in the 1990s, and has been reported to have positive results. Effectiveness of bone marrow cell transfer depends on the osteogenic effect of the transplanted mononuclear cells on the femoral head. This effect is the result of angiogenic cytokines being secreted by stromal bone marrow cells injected into the femoral head and the ensuing angiogenesis. ${ }^{14}$ Hernigou and Beaujean have published on the results of core decompression and bone marrow cell injection in 189 cases. Only nine of 145 patients with stage I or II disease needed total hip replacement. ${ }^{15}$ Gangji et al used core decompression and bone marrow cell injection in 13 patients with stage I or II osteonecrosis of the femoral head, all of whom remained pain-free and did not require total hip replacement during an average follow-up period of 2 years. ${ }^{16}$ In their study in 2011 , Gangji et al divided 24 early-stage hip cases into two groups and used either core decompression or core decompression \pm bone marrow cell injection. These patients were followed up for 5 years. While eight of 11 hips in the control group progressed to the fracture stage, only three of 13 showed progression in the bone marrow group. ${ }^{17}$ Karatoprak et al used CD34+ cell concentrate, known to be both vasculogenic and osteogenic, in nine stage I or II hip cases following core decompression, and over a follow-up period of 27 months, there was no progression and no need for further surgical intervention in any of the cases. 18

Following core decompression, mesenchymal stem cells cultured on a tantalum rod were used to prevent collapse of the joint surface.19 In a study conducted in 2010 in China, porous tantalum rod was suggested for use in the early and intermediate stages.20 Floerkemeier et al compared the results of conventional core decompression and tantalum rods, and reported better results using multiple holes created with $10 \mathrm{~mm}$ wide drills. 21 
Nonvascularized bone grafting can be used to support subchondral bone and joint cartilage by removing necrotic bone tissue and replacing it with a cortical or cancellous bone graft. Three different nonvascularized grafting techniques have become popular over time. Using the Phemister technique, grafting is performed through a core decompression tract. The second method involves grafting performed through a window or a trapdoor in the femoral head. The third method is grafting through a window created at the femoral neck or femoral head-neck junction. 22

In the literature, core decompression and nonvascularized grafting were used in 20 stage I or II hip cases. Tibialautografting, fibular autografting, and fibular allografting were used, respectively, in three, seven, and 10 hips. Cases were followed up for a minimum of 2 years, and positive results were obtained in 17 patients. In 17 hips, the graft was placed within the lesion and adjacent to the subchondral bone. In the remaining three hips, grafts were inserted into the lesion to the level of the transitional zone between the infarct and normal bone. After performing core decompression in 85 hips with ANFH in a study in 2005,Keizer et al use and fibular allografts, respectively, in 18 and 62 patients, respectively. In their surgical series of 47 stage II cases, they reported $44 \%$ revisions and 54\% negative results after an average follow-up period of 4 years, and after 6 years, survival rates were $75 \%$ and $49 \%$ in patients with tibialautografting and fibular allografting, respectively. The authors concluded that grafting position had no effect on the outcome of surgery; however, cortical tibialautografting provided better results due to the osteogenic effect.24 In 2008, a group of investigators reported that the use of cancellous chips supported with bone morphogenetic protein-7 during nonvascularized grafting via a trapdoor technique avoided the need for secondary surgical intervention in $80 \%$ of stage II and III hip cases. 22,24

\section{Conclusion}

Avascular necrosis of femue head primarily affects younger,working age individuals and thus leads to increased morbidity and functional disability.Treatment is aimed at delaying progression of the disease.Our method of core decompression and non vascularized fibular graft provided much pain relief and prevented further progression to majority of the patients.It is a safe and effective procedure for Ficat stage I and II hips.

\section{Conflict Of Interest}

The author(s) declare they have no competing interests.

\section{Acknowledgements}

We thank all the staffs in Department of Orthopaedics in Pariyaram medical college,Kannur,Kerala in completing our study.

\section{References}

[1]. Assouline-Dayan Y, Chang C, Greenspan A, Shoenfeld Y, Gershwin ME (2002) Pathogenesis and Natural History of Osteonecrosis. Semin Arthritis Rheum 32(2): 94-124.

[2]. 10. Hamilton TW, Goodman SM, Figgie M (2009) Sas Weekly Rounds: Avascular Necrosis. HSSJ 5(2): 99-113.

[3]. Kang P, Pei F, Shen B, Zhou Z, Yang J (2012) Are The Results Of Multiple Drilling And Alendronate For Osteonecrosis Of The Femoral Head Better Than Those Of Multiple Drilling? A Pilot Study. Joint Bone Spine 79(1): 67-72.

[4]. Agarwala S, Shah SB (2011) Ten-Year Follow-Up Of Avascular Necrosis Of Femoral head Treated With Alendronate For 3 years. J Arthroplasty 26(7): 1128-1134.

[5]. Evans CH (2012) Gene Delivery To Bone. Adv Drug Deliv Rev 64(12): 1331-1340.

[6]. Camporesi EM, Vezzani G, Bosco G, Mangar D, Bernasek TL (2010) Hyperbaric Oxygen Therapy in Femoral Head Necrosis. J Arthroplasty 25(6 Suppl): 118-123.

[7]. Camp JF, Colwell CW (1986) Core Decompression of the Femoral Head for Osteonecrosis. J Bone Joint Surg Am 68(9): 13131319.

[8]. R Merle d'Aubigne (1964) Idiopathic necrosis of the femoral head in adults. Ann R CollSurgEngl 34: $143-160$.

[9]. Mont MA, Fairbank AC, Krackow KA, Hungerford DS (1996) Corrective osteotomy for osteonecrosis of the femoral head. J Bone Joint Surg Am 78(7): 1032-1038.

[10]. Floerkemeier T, Lutz A, Nackenhorst U, Thorey F, Waizy H (2011) Core Decompression And Osteonecrosis Intervention Rod In Osteonecrosis Of The Femoral Head: Clinical Outcome And Finite Element Analysis. IntOrthop 35(10): 1461-1466.

[11]. Hernigou P, Poignard A, Beaujean F, Rouard H (2005) Percutaneous autologous bone-marrow grafting for nonunions. J Bone Joint Surg Am 87(7): 1430-1437.

[12]. Hernigou P, Beaujean F (2002) Treatment of osteonecrosis with autologous bone marrow grafting. ClinOrthopRelat Res (405): 1423.

[13]. Sen RK, Tripathy SK, Aggarwal S, Marwaha N, Sharma RR, et al. (2012) Early Results of Core Decompression and Autologous Bone Marrow Mononuclear Cells Instillation in Femoral Head Osteonecrosis. J Arthroplasty 27(5): 679-686.

[14]. Zhao D, Cui D, Wang B, Tian F, Guo L, et al. (2012) Treatment Of Early Stage Osteonecrosis Of The Femoral Head With Autologous Implantation Of Bone Marrow-Derived And Cultured Mesenchymal Stem Cells. Bone 50(1): $325-330$.

[15]. Wang BL, Sun W, Shi ZC, Zhang NF, Yue DB, et al. (2010) Treatment Of Nontraumatic Osteonecrosis Of The Femoral Head With The Implantation Of Core Decompression And Concentrated Autologous Bone Marrow Containing Mononuclear Cells. Arch Orthop Trauma Surg 130(7): 859-865. 
[16]. Wang BL, Sun W, Shi ZC, Zhang NF, Yue DB, et al. (2010) Treatment on nontraumatic osteonecrosis of the femoral head with the implantation of core decompression and concentrated autologous bone marrow containing mononuclear cells. Arch Orthop Trauma Surg (2010) 130(7): 859-865

[17]. V Caretti, P Costa, M Mosconi, F Benazzo. Iltrattamentodellanecrosiavascolaredellatestafemorale con core decompression e utilizzo di cellule staminali e fattori di crescita: l'esperienzadellaClinicaOrtopedica. BollettinodellaSocietà Medico Chirurgica di Pavia 123(3): 579-590.

[18]. Song S, Zhu S, Sun C (1998) Treatment of avascular necrosis of femoral head by periosteal cell transplantation : an experimental study. Zhonghua Yi XueZaZhi 78(1): 52-55.

[19]. Mont MA, Baumgarten KM, Rifai A, et al. Atraumatic osteonecrosis of the knee. J Bone Joint Surg Am. 2000;82(9):1279-1290.

[20]. Mont MA, Maar DC, Urquhart MW, et al. Avascular necrosis of the humeral head treated by core decompression. A retrospective review. J Bone Joint Surg Br. 1993;75(5):785-788.

[21]. Mont MA, Marulanda GA, Seyler TM, et al. Core decompression and nonvascularized bone grafting for the treatment of early stage osteonecrosis of the femoral head. Instr Course Lect. 2007; 56:213-220.

[22]. Rajagopal M, Balch Samora J, Ellis TJ. et. al. Efficacy of core decompression as treatment for osteonecrosis of the hip: a systematic review. Hip Int. 2012 Sep-Oct; 22(5):489-93.

[23]. Scully SP, Aaron RK, Urbaniak JR. Survival analysis of hips treated with core decompression or vascularized fibular grafting because of avascular necrosis. J Bone Joint Surg Am. 1998;80(9):1270-1275.

[24]. Simank HG, Brocai DRC, Brill C, et al. Comparison of results of core decompression and intertrochanteric osteotomy for nontraumatic osteonecrosis of the femoral head using Cox regression and survivorship analysis. J Arthroplasty. 2001;16(6):790794.

[25]. Steinberg ME, Larcom PG, Strafford B, et al. Core decompression with bone grafting for osteonecrosis of the femoral head. ClinOrthopRelat Res. 2001;(386):71-78.

[26]. Tofferi JK, Gilliland W. Avascular Necrosis: Differential Diagnoses \& Workup. eMedicine. October 24, 2008. Updated December 2009. Available at: http://emedicine.medscape.com/article/333364-diagnosis. Accessed July 16, 2015.

[27]. von Stechow D, Drees P. Surgical treatment concepts for femoral head necrosis. Orthopade. 2007;36(5):451-457. 